\title{
Erratum to: Overparenting is Associated with Child Problems and a Critical Family Environment
}

Chris Segrin • Michelle Givertz • Paulina Swiatkowski • Neil Montgomery

Published online: 16 November 2013

(c) Springer Science+Business Media New York 2013

Erratum to: J Child Fam Stud

DOI 10.1007/s10826-013-9858-3

The original version of this article unfortunately contained a mistake. The spelling of one of the authors' name was incorrect. It should have read as "Paulina Swiatkowski."

The online version of the original article can be found under doi:10.1007/s10826-013-9858-3.

C. Segrin $(\bowtie)$. P. Swiatkowski

Department of Communication, University of Arizona, Tucson, AZ 85721, USA

e-mail: segrin@u.arizona.edu

M. Givertz

Department of Communication Studies, California State

University, Chico, Chico, CA 95929, USA

N. Montgomery

Department of Psychology, Keene State College, Keene,

NH 03431, USA 